NBER WORKING PAPER SERIES

\title{
ANNUITY PRICES AND SAVING BEHAVIOR \\ IN THE UNITED STATES
}

Benjamin M. Friedman

Mark Warshawsky

Working Paper No. 1683

NATIONAL BUREAU OF ECONOMIC RESEARCH

1050 Massachusetts Avenue

Cambridge, MA 02138

August 1985

The research reported here is part of the NBER's research program in Financial Markets and Monetary Economics. Any opinions expressed are those of the authors and not those of the National Bureau of Economic Research. 


\section{Annuity Prices and Saving Behavior \\ in the United States}

\section{ABSTRACT}

The observed reluctance of most individuals in the United States to buy individual life annuities, and the concomitant approximately flat average age-wealth profile, stand in sharp contradiction to the standard life cycle model of consumption-saving behavior. The analysis in this paper lends support to an explanation for this phenomenon based on the interaction of an intentional bequest motive and annuity prices that are not actuarially fair.

Premiums charged for individual life annuities in the United States include a load factor of 32-48\% per dollar, or 18-33\% per dollar after allowing for adverse selection, in comparison to actuarially fair annuity values. Load factors of this size are not out of line with those on other familiar (and almast universally purchased) insurance products. Simulations of an extended model of life cycle saving and portfolio behavior, allowing explicitly for uncertain lifetimes and Social Security, show that the load factor charged would have to be far larger than this to account for the observed behavior in the absence of a bequest motive. By contrast, the combination of a load factor in this range and a positive bequest motive can do so for some plausible values of the assumed underlying parameters. Moreover, if this combination of factors is leading elderly individuals to avoid purchasing life annuities, it implies a typical bequest that is fairly large in comparison to their consumption.

Benjamin M. Friedman Harvard University Littauer Center 127 Cambridge, MA 02138
Mark Warshawsky

Federal Reserve Board

20th and Constitution streets, N.W. Washington, D.C. 20551 


\section{ANNUITY PRICES AND SAVING BEHAVIOR IN THE UNITED STATES}

\section{Benjamin M. Friedman and Mark Warshawsky*}

One of the most puzzling contrasts between observed behavior and the implications of standard economic theory is the fact that, at least in the United States, few elderly individuals purchase life annuities. The conventional life-cycle model, based on the appealing concept that people save so as to smooth their consumption over their lifetimes, suggests that elderly retired individuals would seek to dissave out of their available resources as their remaining life expectancy shortens. Instead, observed age-wealth profiles among the elderly are more nearly flat. ${ }^{1}$ Given the uncertainty associated with any individual's life expectancy, this reluctance to dissave would be a natural consequence of risk aversion if individuals could not avoid that risk by buying annuities. Since a well-developed individual life annuity market does exist in the United States, however, the challenge is to explain why so few people actually avail themselves of it. ${ }^{2}$

In an earlier paper, the authors offered an explanation for this phenomenon based on a combination of the cost of annuities and a bequest motive. $^{3}$ Annuities are costly, in the first instance, because the insurer must price them to defray ordinary costs of doing business and then earn a competitive profit. In addition, the typical individual in the population finds annuities even more costly because of adverse selection - in other words, the tendency of longer-lived people to buy more annuities than people facing shorter life expectancies. Both kinds of costs understandably discourage the purchase of individual life annuities, within the context 
of the familiar life-cycle model. By contrast, if individuals choose not to buy annuities because they have accumulated wealth to leave to their heirs, rather than to finance their own consumption after retirement, then the life-cycle model - and with it, a variety of well known implications for economic behavior and economic policy - fails to withstand scrutiny. The principal rinding of the authors' earlier research was that during the early years of retirement the observed cost of annuities can independently account for the absence of purchases of individual life annuities, while at older ages the combination of the observed costs of annuities and a bequest motive of plausible magnitude can do so.

The object of this paper is to experiment with an alternative form of the authors' earlier analysis by representing the cost of annuities as the (positive) differential between the premium on an annuity and its implicit expected value, rather than as the (negative) differential between the implicit expected yield on an annuity and the available yield on alternative forms of wealth holding. Given the inverse relationship between price and yield for any fixed-income investment vehicle, in principle these two forms of analysis are simply the duals of one another. The difference here stems from the need to compromise with reality in order to investigate the implications of life annuities within the context of a readily tractable model of the consumption-saving and portfolio-allocation decisions. In effect, the analysis both here and in the authors' earlier paper represents these annuities as if they were one-year contracts. Here, however, the analysis represents the cost of annuities as a one-time proportional charge to enter a market in which actuarially fair annuities are available, while in the earlier paper this cost consists of a continual unfairness in the pricing of the (one-year) annuity contracts. One 
advantage of the approach taken here is that, because large short-sales of annuities are no longer optimal, the nonnegativity constraint that was necessary in the earlier paper is no longer required. Because these formulations of the problem imply alternative opportunity sets, the results given by the two approaches differ.

Section I presents raw data on the prices of individual life annuities sold in the United States during 1968-83, together with transformations of these data that correspond to familiar concepts in economic discussions of consumption-saving behavior. Section II reviews the model of consumptionsaving and portfolio-allocation behavior, for an individual with uncertain lifetimes, developed in the authors' earlier paper. Section III uses simulations of this model, based on the observed pricing of annuities to draw inferences about the respective roles of annuity costs and a bequest motive in accounting for the typical elderly retired individual's preference for maintaining a flat age-wealth profile instead of buying annuities. Section IV briefly sumarizes the paper's principal findings, and re-emphasizes some Iimitations that apply to the analysis here as well as to the authors' earlier work. 
I. Prices of Individual Life Annuities

Table 1 presents data for 1968-83, compiled from successive annual issues of the A.M. Best Flitcraft Compend, on the per-dollar prices of guaranteed single-premium immediate annuities offered in the United States for 65-year-old males. In each case the value shown is the price (premium) charged to purchase a stream of payments equalling $\$ 1$ per month, to begin in the month imediately following the purchase and continue for the life of the annuitant.

The first colum of Table 1 indicates the mean premium charged on this basic annuity contract by the ten largest insurance companies in the United states. These data are probably the most relevant for analyzing economy-wide individual behavior. The largest insurers usually do business in all regions of the country, so that the typical 65 -year-old U.S. male has access to annuities at this mean price with little or no search costs. As would be expected, the average annuity premium has fallen over time, as the effect of rising interest rates has predominated over the effect of increasing life expectancy.

The remaining colums of Table $I$ indicate the potential returns to market search by showing the dispersion of premiums charged for this same basic contract by different insurers. 4 The second and third colums show data for the highest and lowest premiums charged for this contract by any of the ten largest insurers. Presumably most 65-year-old males have access to the lowest premium in this group at only modest search cost. The final colum of the table shows the lowest premium charged for this contract by any of the fifty-odd insurers in Best's sample. Because the smaller companies in the sample do not necessarily maintain sales forces in all parts of the country, however, there is no presumption that the typical 65-year-old male 
TABLE 1

PREMIUMS FOR IMMEDIATE \$1 MONTHLY LIFE ANNUITIES

Ten Largest Insurers

\begin{tabular}{|c|c|c|c|}
\hline Mean & High & Low & Low \\
\hline$\$ 132.10$ & $\$ 136.20$ & $\$ 128.60$ & $\$ 127.20$ \\
\hline 129.90 & 134.30 & 125.20 & 123.90 \\
\hline 127.40 & 133.70 & 119.30 & 116.70 \\
\hline 124.60 & 133.70 & 115.80 & 115.80 \\
\hline 124.70 & 133.70 & 117.70 & 117.70 \\
\hline 123.20 & 131.00 & 117.70 & 117.70 \\
\hline 121.70 & 127.60 & 115.80 & 115.50 \\
\hline 118.70 & 123.80 & 113.30 & 113.30 \\
\hline 116.60 & 123.30 & 111.40 & 107.90 \\
\hline 116.60 & 122.10 & 113.30 & 109.10 \\
\hline 116.60 & 122.10 & 113.30 & 109.10 \\
\hline 117.20 & 122.40 & 113.30 & 105.90 \\
\hline 113.40 & 119.90 & 105.70 & 101.80 \\
\hline 109.00 & 116.60 & 103.20 & 92.30 \\
\hline 104.90 & 116.60 & 87.60 & 75.30 \\
\hline 103.70 & 116.60 & 90.80 & 81.80 \\
\hline
\end{tabular}

Note: Quotations are for 65-year-old males. 
has ready access to this complete-sample lowest premium.

Table 2 presents calculations of the present expected value of an immediate $\$ 1$ monthly annuity for the life of a 65 -year-old male. The two key ingredients in such calculations, of course, are the assumed interest rate and the assumed structure of mortality probabilities. ${ }^{5}$ The table reports annual calculations of present expected value based on two different interest rates, the 20-year U.S. Government bond yield and the average yield on corporate debt directly placed with major life insurance companies. In the calculations underlying the first two colums of the table, the assumed mortality probabilities are the general population mortality probabilities for 65-year-old males reported in the 1970 and 1980 U.S. Iife Tables, adjusted by a factor of .985 to reflect the $1.5 \%$ ammal improvement in $0 . S$. male mortality probabilities that has occurred over the last two decades, and by a further factor of .9925 to reflect the assumption of a future $0.75 \%$ anmual improvement in male mortality probabilities for all ages. 6

Which of the two interest rates used in Table 2 is most relevant depends upon the perspective taken in the analysis. From the standpoint of the actuarial "fair" value to an insurer who has access to (and typically owns) direct placement securities, the associated higher yield is the correct one to choose. Alternatively, from the standpoint of an individual's opportunity cost of funds, the lower yield on U.S. Government bonds is relevant if the individual has no better investment vehicle. Because direct placements bear higher yields than do Government bonds, the present expected values calculated using this yield are smaller than the corresponding values calculated using the Government bond yield. Nevertheless, the present expected values calculated on either basis, including the 
TABLE 2

PRESENT EXPECTED VALUES OF \$I MONTHLY LIFE ANNUITIES

Mortality Probabilities:

\section{Interest Rate:}

1968
1969
1970
1971
1972
1973
1974
1975
1976
1977
1978
1979
1980
1981
1982
1983

1969

1970

1971

1973

1974

1975

1976

1977

1978

1979

1981

1982

1983

\section{iortality Probabilities:}

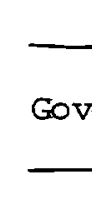

General Population

Government

Bonds

$\$ 104.80$

99.49

96.67

101.41

102.74

96.16

91.23

90.93

93.23

94.83

90.66

86.64

77.43

69.31

72.25

78.69
Direct

Placements

$\$ 92.19$

87.64

80.14

85.84

88.48

88.25

82.23

79.49

83.67

87.88

85.04

80.67

70.21

63.24

65.57

74.38
Annuity Purchasers

$\begin{array}{ccc}\begin{array}{c}\text { Government } \\ \text { Bonds }\end{array} & & \begin{array}{c}\text { Direct } \\ \text { Placements }\end{array} \\ \$ 120.81 & & \\ \text { \$104.80 } \\ 113.81 & & 98.92 \\ 110.04 & & 89.50 \\ 116.59 & & 96.86 \\ 118.06 & & 100.00 \\ 109.46 & & 99.53 \\ 103.07 & & 91.91 \\ 102.52 & & 88.41 \\ 105.20 & & 93.37 \\ 107.01 & & 98.39 \\ 101.65 & & 94.75 \\ 96.56 & & 89.29 \\ 85.61 & & 76.92 \\ 75.75 & 68.57 \\ 79.15 & 71.23 \\ 86.77 & 81.58\end{array}$

Note: Calculations are for 65-year-old males. 
Government bond yield, are always smaller than even the lowest premium charged in the same year by any insurer in Best"s sample.

If all individuals had identical mortality probabilities, a comparison between the calculated present expected values shown in the first two columns of Table 2 and the actual premiums shown in Table 1 would indicate the "load factor" by which the pricing of these annuities differs from their fair actuarial value. In fact, many individuals have information that leads them to expect either a shorter or a longer life than the population-wide average. Insurers, however, typically charge a uniform premium to all individuals of the same age and sex, presumably because information about individual mortality probabilities is either impossible or too costly to obtain and use. Individuals expecting longer (shorter) than average lifespans will therefore perceive life annuities as more (less) attractively priced, and hence will be more (less) likely to buy them. ${ }^{7}$ This adverse selection - adverse from the viewpoint of the insurer, that is - will lead to underwriting losses if the insurer continues to charge a premium that is actuarially fair to the population as a whole.

The final two colums of Table 2 therefore present the results of further annual calculation of the present expected value of the same basic annuity contract for a 65 -year-old male, based on the same two interest rates as before, but now based on alternative mortality probabilities compiled from the actual company experience on individual life annuity contracts issued in the United States during 1971-75, again adjusted as indicated above to reflect the improvement in mortality probabilities. ${ }^{8}$ Figure 1 indicates the extent to which the sub-population who choose to buy annuities in fact have a greater survival probability than the general population. Because of this greater life expectancy, the present expected values shown in the 
PROBABILITY OF MALE AT AGE 65 SURVIVING TO AGE $\mathrm{x}$

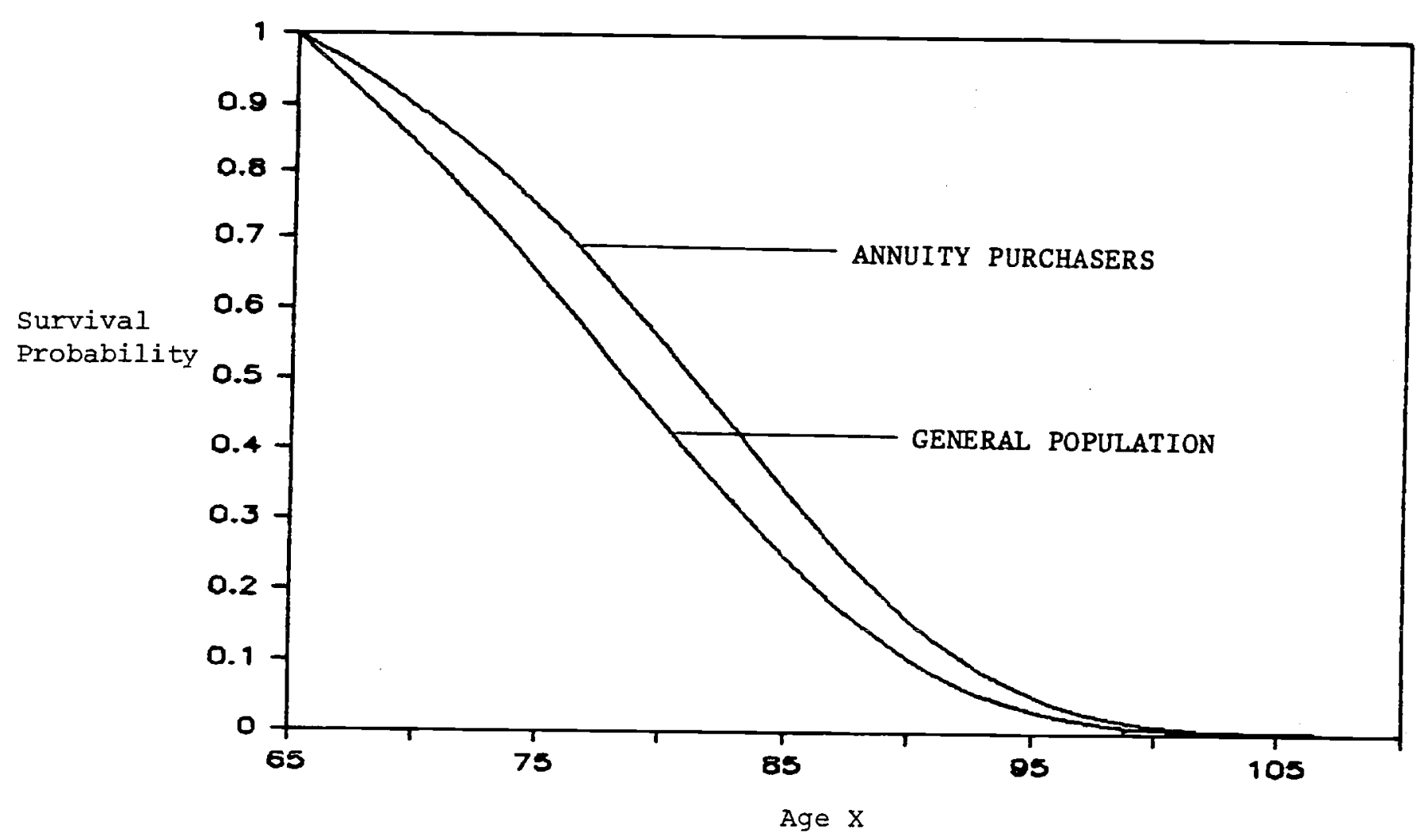


last two columns are greater than the corresponding values shown in the table's first and second columns, respectively, based on the same two interest rates but on general population mortality probabilities. Even the greater values resulting from the actual company experience mortality probabilities, however, are still uniformly smaller than even the lowest corresponding premiums shown in Table 1. Even within the sub-population who voluntarily buy annuities, therefore, the price is not actuarially fair.

Table 3 sunmarizes the differences between the actual premiums charged on this basic annuity contract and the corresponding actuarially fair values by showing the 1968-83 average of the ratio of premium charged to present expected value, for each of the four premiums reported in Table 1 and each of the four present expected value calculations reported in Table 2 . The resulting average load factors range from a low of 1.06 for the smallest premium charged by any company in Best's sample, compared to the present expected value based on Government bond yields and actual company experience mortality probabilities, to a high of 1.55 for the largest premium charged by any of the ten largest insurers, compared to the present expected value based on direct placement yields and general population mortality tables. The comparisons in Table 3 that are probably most relevant for studying economy-wide individual behavior are those shown in the first row for the mean premium charged by the ten largest insurers versus the present expected value based on either Govermment bond yields or direct placement yields, and on either general population or company experience mortality probabilities. The load factor of 1.32 for the first case considered means that a 65-year-old U.S. male, randomly selected from that population, and for whom the Government bond yield represents the opportunity cost of capital, typically pays $\$ 1.32$ for each $\$ 1.00$ of expected present value when he purchases a life annuity. 


\section{TABLE 3}

\section{MEAN LOAD FACTORS ON LIFE ANNUITY PREMIUMS}

Mortality Probabilities:

Interest Rate:

Premium:

Ten-Iargest Mean
Ten-Iargest High
Ten-Iargest Low
Complete-Sample Io

General Population

\begin{tabular}{cc}
\hline $\begin{array}{c}\text { Government } \\
\text { Bonds }\end{array}$ & Direct \\
\hline
\end{tabular}

Annuity Purchasers

Government Direct Bonds Placements

$\begin{array}{llll}1.32 & 1.48 & 1.18 & 1.33 \\ 1.39 & 1.55 & 1.24 & 1.40 \\ 1.24 & 1.39 & 1.11 & 1.25 \\ 1.20 & 1.34 & 1.06 & 1.20\end{array}$

Wote: Calculations are for 65-year-old males. 
Among the (on average longer-lived) sub-population of 65-year-old U.S. males who actually choose to buy life annuities, the load factor based on the same opportunity cost is only 1.18. In other words, of the $32 \mathrm{c}$ per dollar load factor to the general population, $14 \%$ represents the effect of adverse selection and the remaining $18 \dot{c}$ the combination of transactions costs, taxes and profit to the insurer. If the annuity purchaser's opportunity cost of capital is instead the direct placement yield - for example, because of ability to buy shares in packages of intermediated private securities - then the load factor per dollar of expected present value is $48 \%$, of which $15 \%$ represents the effect of adverse selection and the remaining 33 the insurer's costs, taxes and profit. ${ }^{9}$. As the Appendix Table shows, these results for 65 year-old males are similar to those for females, or for males of different ages.

The question for consurmtion-saving behavior, then, is whether an average load factor of 1.18 (or even 1.48 ) is sufficient to account for the small participation in the individual life annuity market in the United States. In short, do most elderly retired people choose not to consume out of their wealth, and therefore leave unintentional bequests, merely because they are reluctant to pay $\$ 1.18$ (or $\$ 1.48$ ) for every $\$ 1.00$ of present expected value of annuities?

It is difficult to answer this question on the basis of casual evidence only. At first thought, a load factor of this magnitude seems a large price to pay for pooling risk. Nevertheless, it is not out of line with loads charged elsewhere in the insurance business, in product lines that almost everyone buys. For example, data from Best's Key Rating Guide: Property-Casualty indicate that the recent average load factor in premiums charged for property and casualty insurance written by large companies has been 1.37 - essentially the same as that on individual life annuities. 
Moreover, despite the apparently large load factor, individual life annuities are not a "dominated asset" in the sense that the cost per unit of pay-off, unadjusted for mortality probabilities, is greater than the analogous cost of alternative investment vehicles. Table 4 shows the present value of a 35-year certain $\$ 1$ monthly annuity, calculated using the two interest rates used in Tables 1 and 2 , respectively, for each year during $1968-83 .{ }^{10}$ As comparison to the first column of Table 1 shows, the value of the certain annuity based on the government bond yield exceeded the mean premium on the life annuity charged by the ten largest insurers in all years of the sample except 1980-82, while the value based on the direct placement yield exceeded the mean premium in all years until 1979.

Hence some more formal approach to this issue is necessary. Section II develops a framework for such an analysis, and section III applies that framework in the context of the premium and load factor data reported here. 
TABLE 4

PRESENT VALUE OF A 35-YEAR CERTAIN \$1 MONTHLY ANNUITY

\begin{tabular}{crc} 
Interest Rate: & Government Bonds & Direct Placements \\
\cline { 2 - 3 } 1968 & $\$ 190.41$ & \\
1969 & 172.26 & $\$ 153.04$ \\
1970 & 162.68 & 139.60 \\
1971 & 176.32 & 120.14 \\
1972 & 178.51 & 133.88 \\
1973 & 158.30 & 139.47 \\
1974 & 144.21 & 137.77 \\
1975 & 142.28 & 122.38 \\
1976 & 146.91 & 115.40 \\
1977 & 149.69 & 123.96 \\
1978 & 138.42 & 132.79 \\
1979 & 128.12 & 125.35 \\
1980 & 108.21 & 115.03 \\
1981 & 91.80 & 93.95 \\
1982 & 96.86 & 80.87 \\
1983 & 108.96 & 84.62 \\
& & 100.45
\end{tabular}


II. A Model of Saving and Annuity Demand 11

The model used in Friedman and Warshawsky (1985) to analyze the demand for individual life annuities in the context of life-cycle saving and a bequest motive is an annuity analog of Fischer's (1973) model of the demand for life insurance, generalized to incorporate fixed mandatory holdings of socially provided annuities. ${ }^{12}$ The individual's decision problem in this expanded life-cycle context is to maximize expected lifetime utility

$E(U)=\sum_{t=0}^{w-x-1}\left[p_{t} U_{t}\left(C_{t}\right)+p_{t} q_{t+1} V_{t+1}\left(G_{t+1}\right)\right]$

where $w$ is the assumed maximum length of life, $x$ is the individual's age as of time $t=0, p_{t}$ is the probability that an individual of age $x$ at $t=0$ will be alive at any time $t \geq 0, q_{t+1}$ is the (conditional) probability that such an individual who was alive at time $t$ will die at time $t+1 .{ }^{13}$

$U_{t}\left(C_{t}\right)$ is utility received from consumption $C$ at time $t$, and $v_{t+1}\left(G_{t+1}\right)$ is utility received from (anticipation of) a bequest $G$ at time $t+1$. Following Fischer, it is convenient to specify the two utility functions in the iso-elastic form

$u_{t}\left(c_{t}\right)=\frac{c_{t}^{1-\beta}}{1-\beta} \cdot \alpha^{t}$

$v_{t}\left(G_{t}\right)=\frac{G_{t}^{1-\beta}}{1-\beta} \cdot b_{t}$

where $\beta$ is the Pratt-Arrow coefficient of relative risk aversion, $\alpha$ is the time preference parameter, and $b_{t}$ (in comparison to $\alpha^{t}$ ) indicates the relative utility attached to bequests left in period $t$.

The usual life-cycle specification of behavior with no bequest motive is therefore just the speical case of this model with $b_{t}=0$ for all $t>0$. 
In general, however, people may value bequests, and they may value them differently at different times. The application of the model in section III below follows Yaari's suggestion that $b_{t}$ follows a hump-shaped pattern with higher values during the years when family dependency is important, so that $b_{t}$ is declining during retirement years when children have typically become independent.

The individual's problem is to maximize (1) subject to a given initial wealth position and to a nonnegativity constraint on wealth in each subsequent time period, given the menu of available investment opportunities (including any mandatory holding of socially provided annuities) and their respective yields. ${ }^{14}$ In each period the individual must decide not only how much of current wealth to consume but also how to allocate the remainder among the available investment vehicles. The specific asset menu considered here includes a riskless one-period bond bearing gross rate of return $R_{t}$, a one-period social annuity bearing gross rate of return $Q_{t}^{S}$ to survivors, and a one-period market annuity bearing gross rate of return $Q_{t}^{A}$ to survivors. 15 Both annuities are actuarially fair - that is, there is no load factor on either - if

$$
\left(1-q_{t+1}\right) Q_{t}^{S}=\left(1-q_{t+1}\right) Q_{t}^{A}=R_{t}
$$

with little relevant loss of generality, it is convenient to set $R_{t}$ constant at $R$ for all $t \geq 0$.

The dynamic programming solution to this problem proceeds from the final period $t=w-x-1$, in which the certainty of death at the end of the period $\left(q_{w-x}=1\right)$ simplifies the problem of an individual who has survived to that date to merely choosing $\mathrm{C}_{\mathrm{w}-\mathrm{x}-1}$ to maximize the sum of utility from current consumption $U_{w-x-1}\left(C_{w-x-1}\right)$ and utility from bequests $v_{w-x}\left(G_{w-x}\right)$, subject to then-remaining wealth $\mathrm{w}_{\mathrm{w}-\mathrm{x}-1}$ and the constraint 
$G_{w-x}=R \cdot\left(W_{w-x-1}-C_{w-x-1}\right)$

Given the iso-elastic utilities assumed in (2) and (3), the solution is just

$c_{w-x-1}=k_{w-x-1} \cdot w_{w-x-1}$

where

$k_{w-x-1}=\frac{R\left(R b_{w-x}\right)^{-1 / \beta}}{1+R\left(R b_{w-x}\right)^{-1 / \beta}}$

and the corresponding indirect utility function

$J_{1}\left[W_{w-x-1}\right]=\max _{C_{w-x-1}}\left\{U_{w-x-1}\left(C_{w-x-1}\right)+v_{w-x}\left(G_{w-x}\right)\right\}$

is

$J_{1}\left[w_{w-x-1}\right]=\delta_{w-x-1} \cdot \frac{w_{w-x-1}^{1-\beta}}{1-\beta}$

where

$\delta_{w-x-1}=k_{w-x-1}^{-\beta}$

The consumption decision (5) represents the entire solution for $t=w-x-1$, since in that period the availability of annuities is irrelevant to the analysis.

The dynamic programming solution next proceeds to the individual's optimal consumption and portfolio decisions for the immediately prior period, given wealth remaining at that time. An individual alive at $t=w-x-2$ will die at the end of that period with probability $q_{w-x-1}$. Hence the relevant maximand governing the decisions to be taken as of $t=w-x-2$ is $U_{w-x-2}\left(C_{w-x-2}\right)$ plus the bequest motive $v_{w-x-1}\left(G_{w-x-1}\right)$ with probability $q_{w-x-1}$ and the indirect utility function in (9) with probability $\left(1-q_{w-x-1}\right)$. The indirect 
utility function for $t=w-x-2$ is therefore

$$
\begin{aligned}
& J_{2}\left[w_{w-x-2}\right]=\max _{C_{w-x-2}{ }^{A}{ }_{w-x-2}}\left\{\frac{C_{w-x-2}^{1-\beta}}{1-\beta}+\left(1-q_{w-x-1}\right) \alpha \delta_{w-x-1} \cdot \frac{\left(w_{w-x-2}-C_{w-x-2}\right)^{1-\beta}}{1-\beta}\right. \\
& \text { - }\left[R\left(1-A_{w-x-2}-S_{w-x-2}\right)+Q_{w-x-2}^{A}{ }_{w-x-2}+Q_{w-x-2}^{S}{ }_{w-x-2}\right]^{1-B} \\
& +q_{w-x-1} b_{w-x-1} \cdot \frac{\left(w_{w-x-2}-c_{w-x-2}\right)^{1-\beta}}{1-\beta} \cdot\left[R\left(1-A_{w-x-2}-s_{w-x-2}\right)\right]^{1-\beta}
\end{aligned}
$$

where $A$ and $S$ are the proportions of saving $(W-C)$ invested in market annuities and (mandatorily) in social annuities, respectively. The usual life-cycle model with no market for annuities is therefore just the special case represented by $A_{t}=0$ for all $t \geq 0$ (and, if there are no social annuities either, $s_{t}=0$ for all $t \geq 0$ also). 16

The first-order conditions for (11) then give the optimal values of consumption and purchases of market annuities at $t=w=x-2$ as

$$
C_{w-x-2}=\delta_{w-x-2}^{-1 / \beta} \cdot w_{w-x-2}
$$

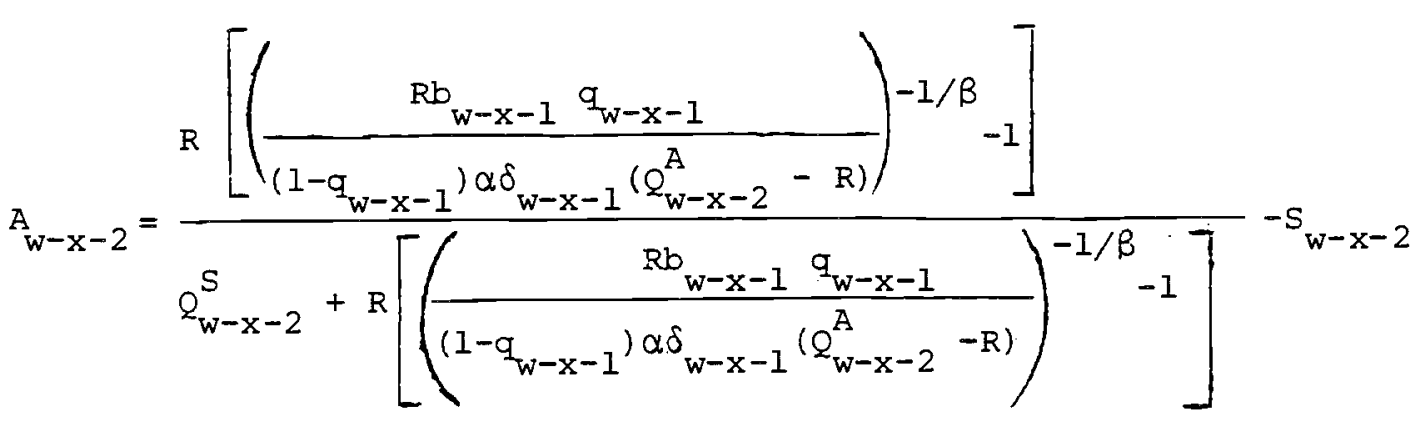

and the corresponding value of the indirect utility function as

$$
J_{2}\left[w_{w-x-2}\right]=\delta_{w-x-2} \cdot w_{w-x-2}
$$


$\delta_{w-x-2}=\left[\frac{k_{w-x-2}}{1+k_{w-x-2}}\right]^{-\beta}$

and

$$
\begin{aligned}
k_{w-x-2} & =\left[\alpha \delta_{w-x-1}\left(R\left(1-A_{w-x-2}-S_{w-x-2}\right)+Q_{w-x-2}^{A}{ }_{w-x-2}+Q_{w-x-2}^{S} S_{w-x-2}\right) 1-B\right. \\
& +b_{w-x-1} q_{w-x-1}\left(R\left(1-A_{w-x-2}-S_{w-x-2}\right)\right)^{1-B_{]}-1 / B} .
\end{aligned}
$$

The remainder of the dynamic programming solution proceeds backward to the initial period $t=0$ in an analogous way. The expressions for each period's optimal consumption and purchases of market annuities, and for each period's value of the indirect utility function, are of the same form (but with subscripts adjusted accordingly) as (12), (13) and (14), respectively. 
III. Simulation Results

The model developed in section II generates lifetime streams of consumption and annuity purchase values that are optimal for given values of parameters describing preferences $(\beta, \alpha$ and $b)$, the market environment $\left(R, Q^{A}\right.$ and $\left.Q^{S}\right)$, and mortality probabilities ( $p$ and $q$ ). The principal focus of interest in this paper is on one aspect of preferences and one aspect of the market environment - the bequest motive and the availability of market annuities, respectively.

The strategy adopted here for representing the bequest motive (confronting a 65-year-old male) follows Fischer (1973) by assuming that $b_{t}$ in (3) varies according to

$b_{t}=(1.04-.01 t) \cdot \theta, \quad t=0, \ldots, 35$

where $\theta$ is a non-age-specific parameter indicating the individual's lifelong preference for bequests relative to current consumption, given the other parameters of the model, including in particular the interest rate $(R)$, the curvature of the utility function ( $\beta$ ), and - because $\theta$ implicitly gives the relative weight of a stock (the bequest) versus a flow (consumption) - the assumed time unit of analysis. For any given value of $\theta$, however, $b_{t}$ declines linearly with $t .{ }^{17}$ Given $\theta$ and $b_{t}$, the bequest amount is larger as $R$ is higher, and smaller as $\beta$ is higher. For example, from (5) $-(7)$ and (17), $\theta$ takes the value $\left(G_{w-x} / C_{w-x-1}\right)^{\beta} \cdot(.69) / R$, where $\left(G_{w-x} / C_{w-x-1}\right)$ is just the ratio of the final-period bequest to the priorperiod consumption. The normally limiting case for altruistic bequests, in which an individual provides for his heirs' consumption at the same level as his own, indicates $(1 / R-1)^{\beta} \cdot(.69) / R$ as the logical upper bound on $\theta .18$ In the simulations reported below, the strength of the bequest 
motive is indicated initially by $\theta$, and subsequently by the corresponding bequest/saving ratio $\left(G_{w-x} / C_{w-x-1}\right)$ given the other assumed parameters. The strategy used here to represent the market for private annuities follows Kotlikoff and Spivak (1981) by assuming that private annuities are either available at the actuarially fair price $Q^{A}=R /(1-q)$, or, alternatively, not available at all $(A=0)$. The object of the analysis, therefore, is to determine what load factor an individual would be willing to pay in order to have access to market annuities under the assumed values of all of the model's other parameters. By comparing this critical load factor with the typical load factors sumnarized in Table 3 , in light of the observation that in fact only few individuals actually purchase life annuities, it is then possible to assess the reasonableness of the assumed values of the model's other parameters - including, in particular, the strength of the bequest motive.

This treatment of the cost of annuities captures the chief implications of the fact that, although the model in principle refers to one-period annuities, in fact the annuities available for purchase are life annuities. Even when an individual makes monthly annuity purchases over time, as in many defined contribution retirement plans, what he is buying each month is an additional life annuity. It is therefore plausible to treat the load factors or annuity premiums shown in Table 3 in a lump-sum fashion, not as a load to be repeated in every period. The simplest place to begin is the special case of the model developed in section II corresponding to the standard life cycle model with neither bequest motive nor social security (which is equivalent to the model in Kotlikoff and Spivak). Table 5 summarizes the results of two simulations of the model, both based on the assumptions that $b_{t}=0$ and $s_{t}=0$ for all $t$. As in Kotlikoff and Spivak's work, the assumed time 


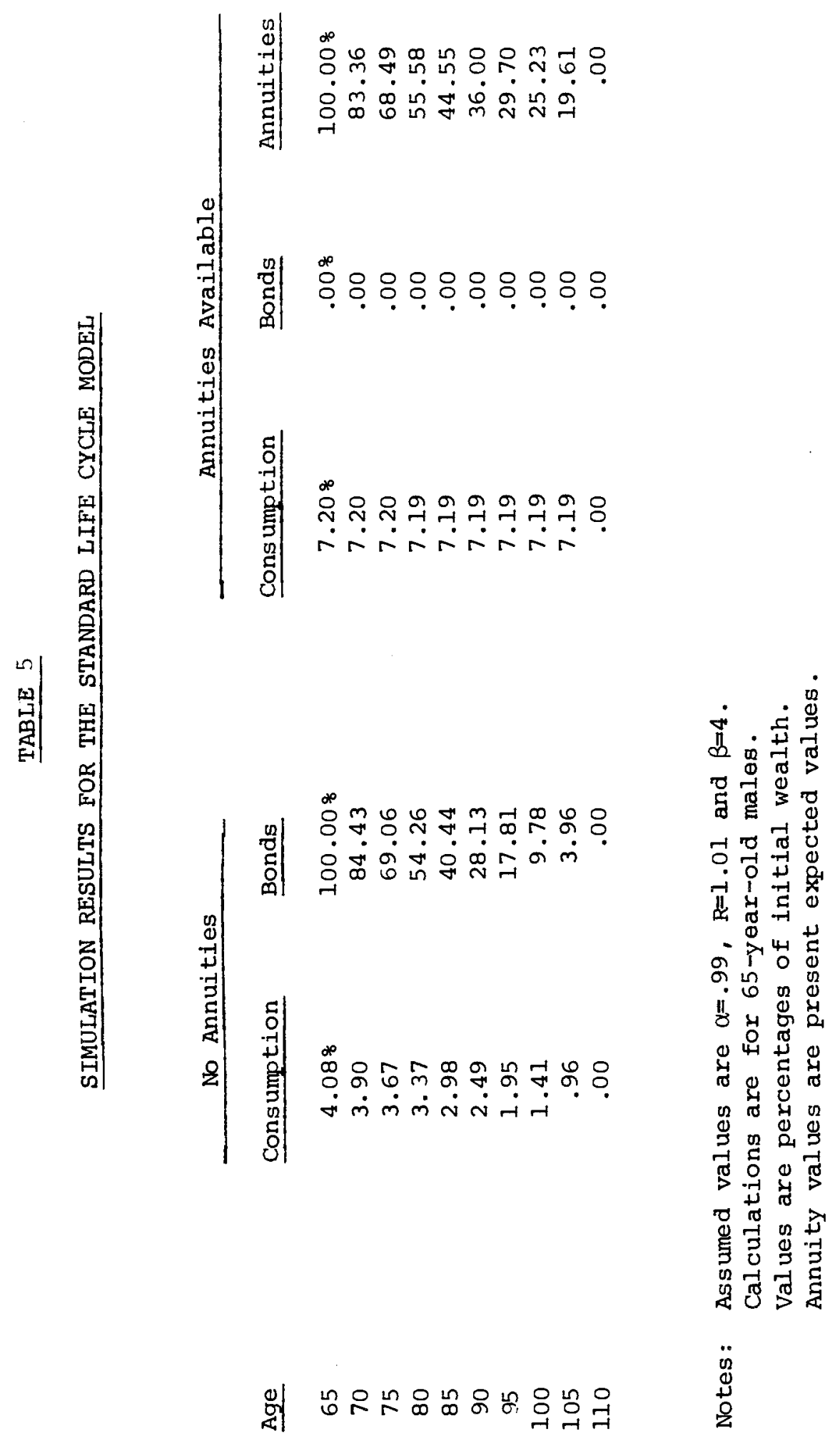


preference parameter is $\alpha=.99$, and the assumed market interest rate is constant at $R=1.01$. The assumed coefficient of relative risk aversion is $\beta=4.19$ The assumed mortality probabilities are those for a 65 -year-old male reported in the 1980 U.S. Life Tables, adjusted as described in section I. For each simulation, Table 5 shows the relevant solution values for the initial year (age 65) and every fifth year thereafter until the assumed maximum life span (age 110).

The first simulation considered within this traditional life cycle context represents the case in which market annuities (like social annuities here) are unavailable. The individual's only choice is therefore how much to consume in each period, since the unconsumed portion of initial wealth is automatically invested in one-year bonds. The first colum of Table 5 shows the optimal age-consumption profile, while the second column shows the corresponding implied profile of remaining wealth (consisting entirely of bonds), with both sets of values stated as percentages of initial wealth. These simulated values immediately indicate the important contrast between reality and the model's assumptions, in that they show the optimality of a declining age-consumption profile and a sharply declining age-wealth profile - phenomena not observed in available dáta.

The second simulation within this traditional life cycle context, sumarized in the remaining colums of Table 5, shows that simply relaxing the assumption that market annuities are unavailable avoids this strikingly counterfactual result only at the expense of leading to another. This simulation differs from the first one in assuming that individual life annuities are available in the private market at an actuarially fair price $\left(Q^{A}=R /(1-q)\right)$, and the table reports values for optimal consumption as well as optimal wealth holdings in bonds and annuities, respectively. ${ }^{20}$ In this case, the individual's optimal course of action is to hold no bonds at all 
but to stabilize the age-consumption profile almost completely by investing all wealth in annuities. The implied flat age-consumption profile is roughly consistent with the available evidence, but the implied large demand for market annuities is sharply counterfactual.

Following Kotlikoff and Spivak, it is possible to infer the lump-sum value to the individual, under the conditions assumed in the simulations reported in Table 5, of having access to a market for actuarially fair life annuities. From (14), the initial value of the indirect utility function in each simulation is

$J_{w-x}\left[w_{0}\right]=\delta_{0} \frac{w_{0}^{1-\beta}}{1-\beta}$

for given initial wealth $W_{0}$. The proportional increment in the individual's initial wealth required to render the individual as well off, in the sense of an equal initial value of the indirect utility function, in the absence of an annuity market as with such a market is therefore just

$M=\left[\frac{\delta_{0} \mid Q^{A}=R /(1-q)}{\delta_{0} \mid A=0}\right]^{\frac{1}{1-B}}-1$

where $\delta_{0} \mid Q^{A}=R /(1-q)$ is the value of $\delta_{0}$ in (18) in the simulation with a market for fair annuities and $\delta_{0} \mid A=0$ is the analogous value in the simulation with no annuity market.

For the pair of simulations reported in Table 5, the calculation in (18) yields $M=1.13$. Under the conditions assumed in these simulations, therefore, it would still be preferable to put all of initial wealth into annuities than to buy none at all, as long as the load factor did not exceed $L^{*}=2.13 .^{2}$. Because $L^{*}=2.13$ far exceeds the load factors in actual annuity prices calculated on any of the bases reported in Table 3 , and yet in fact 
there is little individual demand for life annuities, some other assumption common to the two simulations shown in Table 5 must be importantly counterfactual. One possibility, of course, is that $\beta=4$ overstates the coefficient of relative risk aversion. Alternative simulations with a smaller risk aversion parameter show that this is not the source of the problem, however. Table 6 summarizes a pair of simulations that are identical to those reported in Table 5 except for the new assumption $\beta=2 .^{22}$ Although the specific age-consumption and age-wealth profiles shown in Table 6 differ somewhat from those in Table 5, the same counterfactual implications are again readily apparent. Indeed, because of the lower risk aversion the optimal age-consumption and age-wealth profiles when annuities are unavailable decline even more sharply. When actuarially fair annuities are available, it is again optimal to invest all of initial wealth in them. Most importantly, even with lower risk aversion the proportional increment in initial wealth required to render the individual as well off in the absence of an annuity market as with such a market is still $M=.88$. Even with lower risk aversion, therefore, it would still be preferable to put all of initial wealth into annuities than to buy none at all, as long as the load factor did not exceed $I^{\star}=1.88$ - a critical value again well in excess of any of the observed load factors reported in Table 3.

A further possible explanation for the counterfactual results in both Tables 5 and 6 is that social security not only exists but is a large part of wealth for most individuals. Table 7 presents a pair of simulations of the more general model developed in section II - first without, and then with, a market for actuarially fair annuities - based on the assumption that actuarially fair social security constitutes half of total wealth $(S=.5) .23$ In all other respects, including the absence of a bequest motive, these 


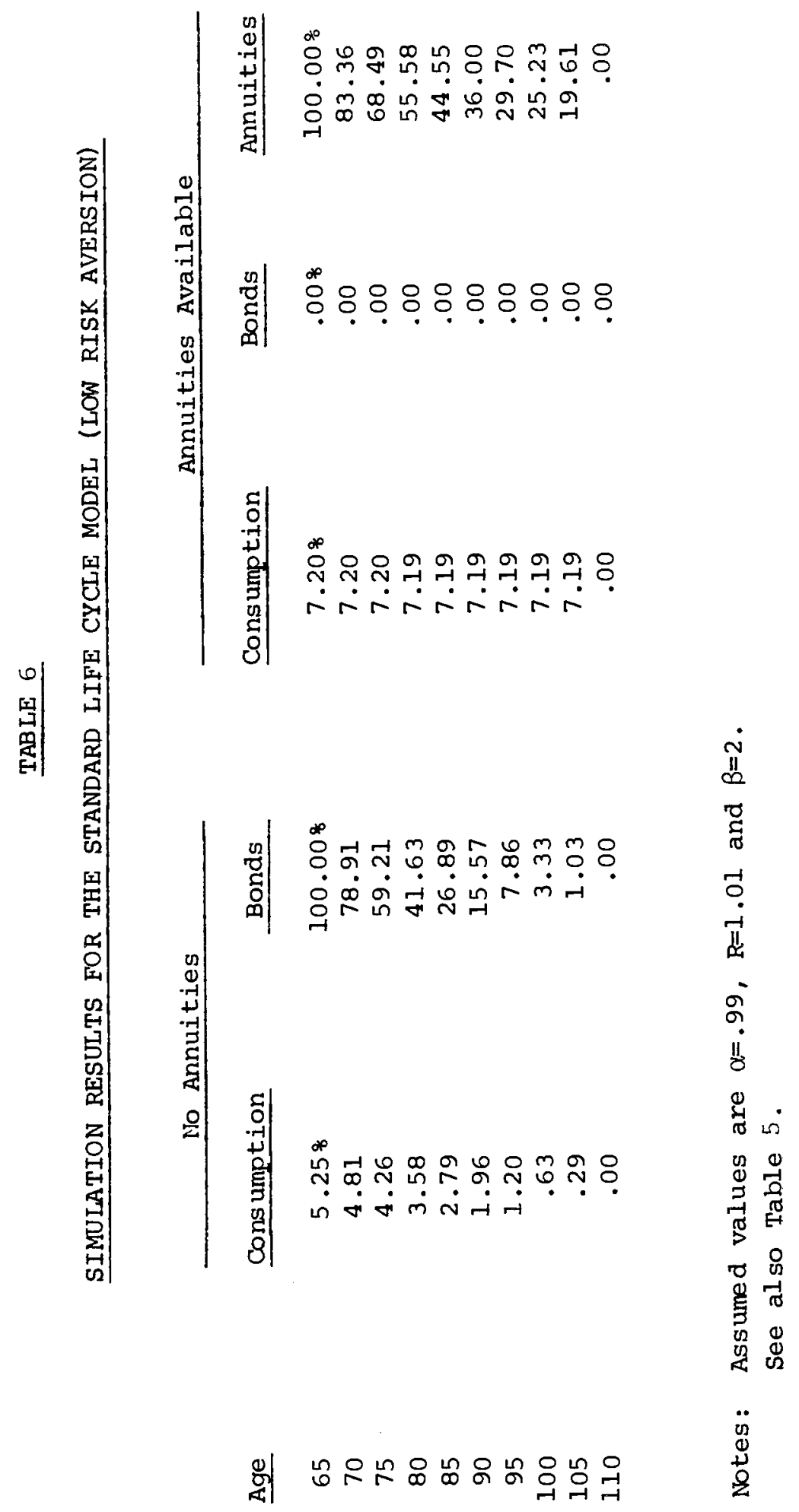




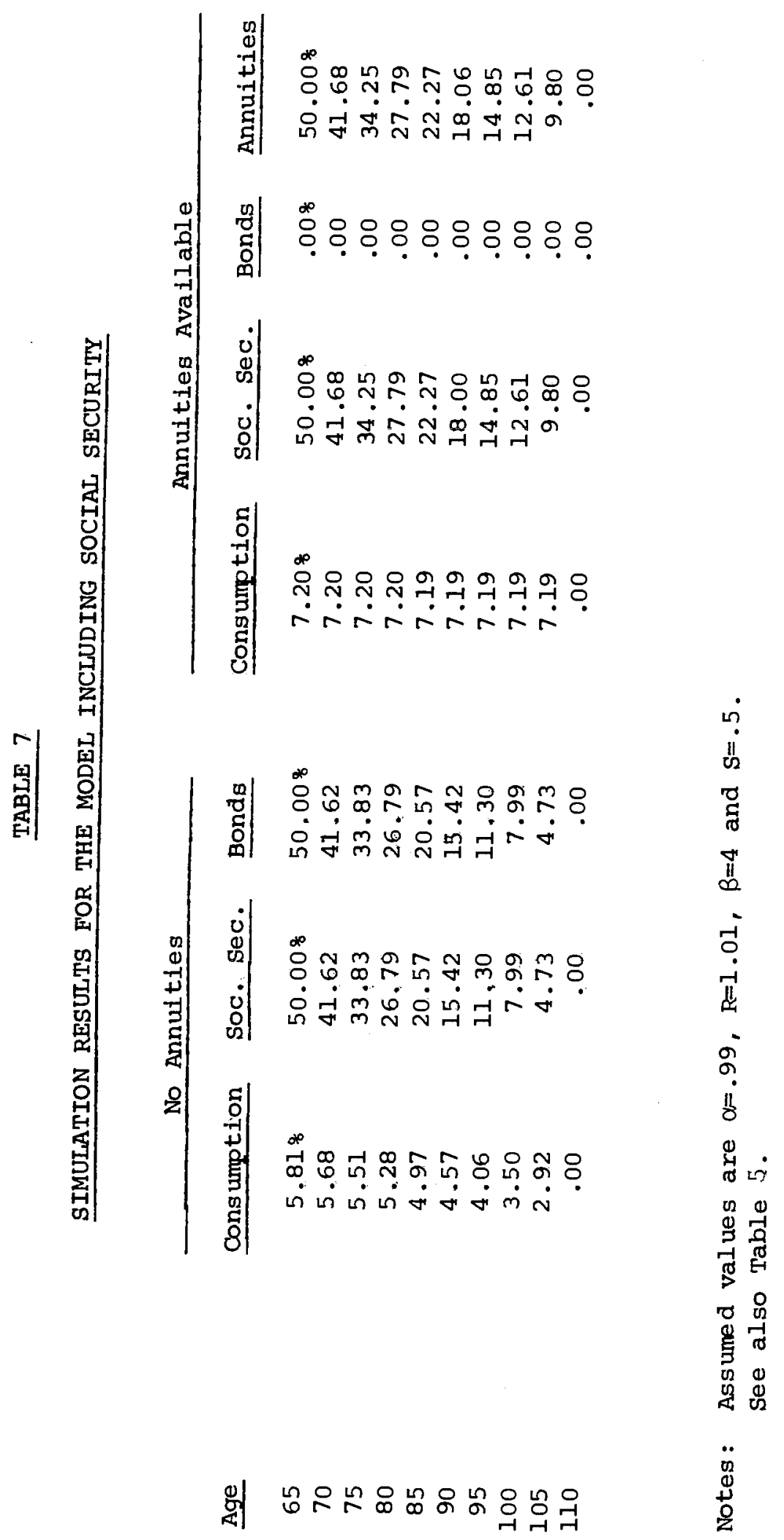


simulations are analogous to those reported in Table 5.

The results shown in Table 7 again exhibit largely the same counterfactual patterns as in Table 5, and therefore suggest that merely allowing for Social Security cannot account for the observed behavior either. In the absence of an annuities market, the optimal age-consumption and especially age-wealth profiles decline fairly sharply, although not so much so as in Table 5. If actuarially fair annuities are available, it is optimal to invest all of total wealth other than social Security in purchasing them. Most importantly, even with a sizeable role for social Security the proportional initial wealth increment required to render the individual as well off without as with a private annuity market is $M=.33$. Hence it would still be preferable to put all of total wealth other than Social security (that is, one-half of total wealth) into private annuities rather than buy none at all, as long as the annuity load factor did not exceed $L^{*}=1.66(=1+.33 / .5)$ - again far greater than the load factors actually observed. An analogous simulation based on the lower risk aversion value of $\beta=2$ (not shown in the table) produces almost identical results, with $M=.31$ and a critical load factor $L^{\star}=1.62$.

The potential explanation for the observed behavior that is of greatest interest in the context of this paper is that, in general, people may value not just their own consumption but also bequests. Table 8 presents three further pairs of simulations of the fully general model developed in Section II, in each case based on the same assumptions as in Table 7

- (including the prominent role for Social security) and, in addition, a positive bequest motive. The first of these three pairs of simulations assumes the bequest motive $\theta=2$, which is quite modest given the stock-flow dimension of $\theta$, and the model's use of an annual time unit, and $\beta=4$. The second pair of simulations assumes $\theta=8$. The third pair assumes $\theta=24$. 


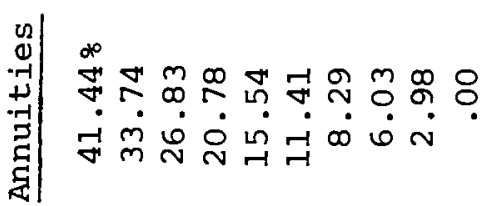

เึ้

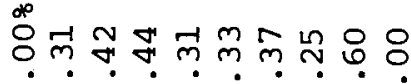

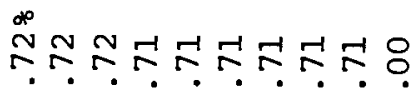
ن ف ف فن ف فن فن 융

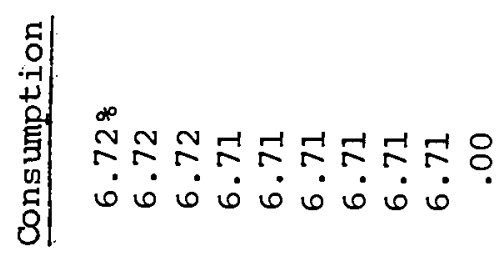

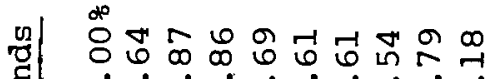

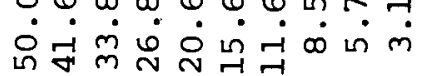

융ำ

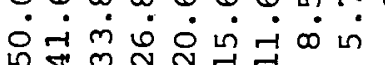

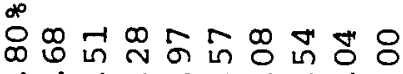

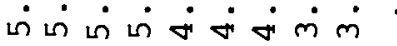

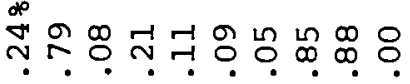
$\dot{m} \dot{m} \dot{\sim} \dot{\sim} \dot{\sim} \dot{m} \dot{\sigma} \dot{\omega} \dot{m}$

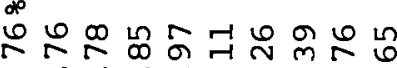

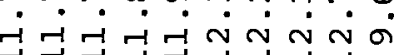

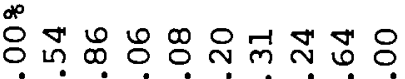

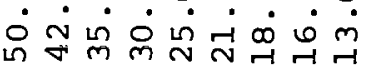

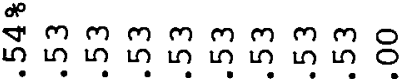
ن

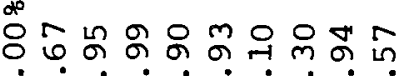
$\dot{0} \dot{\forall} \dot{m} \dot{0} \dot{0} \dot{\sim} \dot{0} \dot{0}$

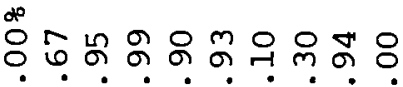
$\dot{\circ} \dot{\sim} \dot{m} \dot{\sim} \dot{\sim} \dot{\sim} \dot{\sim} \sigma \dot{0}$

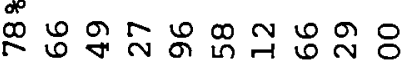

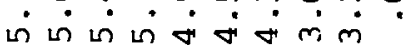

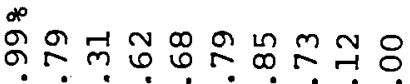

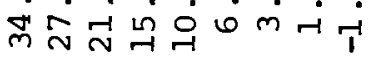

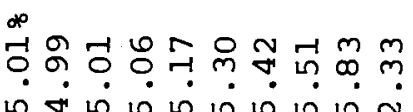

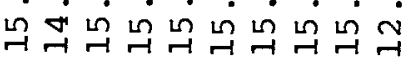

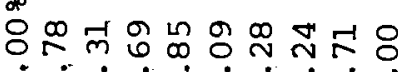
ல் $\dot{0} \dot{0} \dot{\sim} \dot{\sim} \dot{\sim}$

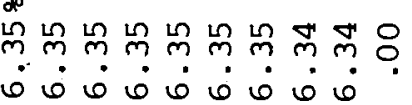

i.

gั

央는

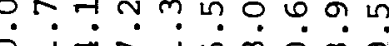

虽

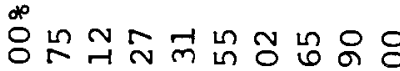

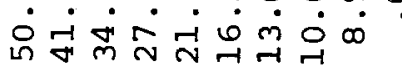

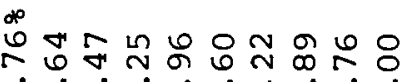

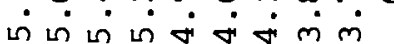

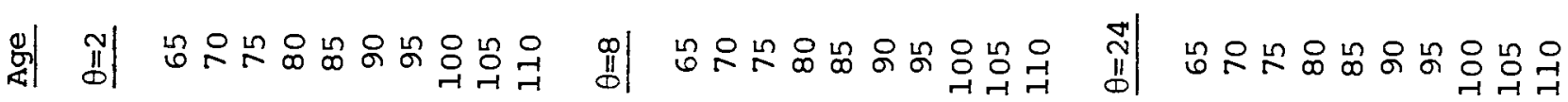


The simulation results reported in Table 8 show that even a very modest bequest motive is sufficient to eliminate one of the importantly counterfactual aspects of the earlier simulations. In particular, because of the bequest motive it is no longer optimal to invest all of total wealth other than social security in private annuities. The fraction of wealth invested in bonds varies positively with the strength of the bequest motive, but even $\theta=2$ is sufficient to make optimal bond holdings neither zero nor trivially small. Moreover, optimal bond holdings do not decrease (until the final year they actually increase slightly) with age. Hence the general model, with even a modest positive bequest motive, is consistent with observed behavior in implying an approximately flat age-wealth profile for the part of wealth held in non-annuity form.

By contrast, the results for all three pairs of simulations shown in Table 8 continue to be counterfactual in implying that, when private annuities are available, it is optimal to use a large fraction of total wealth other than social security to purchase them. Further analysis, however, indicates that here the load factor in annuity pricing is potentially very important.

For the weak bequest motive $\theta=2$, the proportional initial wealth increment required to render the individual as well off without as with a private annuity market is $M=.22$. The critical load factor necessary to make buying no annuities at all preferable to investing $41 \%$ of initial wealth in annuities is therefore $L^{*}=1.53(=1+.22 / .41)$, again above the observed load factors reported in Table 3 for the mean premiums charged by the ten largest insurers, regardless of the mortality probabilities and the interest rate used in the calculations.

For $\theta=8$, the initial wealth increment required to render the individual 
as well off without as with a private annuity market is only $M=.18$, so that the critical load factor that would make buying no annuities at all preferable to investing $38 \%$ of initial wealth in annuities is $L^{\star}=1.47$. As Table 3 shows, this load factor is approximately equal to that charged on average by the largest ten insurers if the underlying present expected value calculation relies on general population mortality probabilities and the interest rate on corporate direct placements. Nevertheless, it still exceeds the implied load factor confronting an individual who knows that his mortality probabilities are characteristic of other annuity purchasers, or whose opportunity cost of funds is the government bond yield (or who searches for the lowest available premium).

Finally, for $\theta=24$, the initial wealth increment required to render the individual as well off without as with a private annuity market is $M=1.14$. Fence the critical load factor that would make buying no annuities at all preferable to investing $35 \%$ of initial wealth in annuities is $L^{*}=1.40$, about in the middle between the actual load factor based on general population mortality probabilities and the direct placement yield and the actual load factor based on alternative assumptions.

Under some sets of plausible assumptions, therefore, importantly including a positive bequest motive, the actual load factor included in the premiums on individual life annuities sold in the United States is sufficient to make people prefer buying no annuities at all over buying the amount that would be optimal if annuity prices were actuarially fair. Although this finding is hardly without interest, since it indicates a joint role for the bequest motive and for annuity load factors in explaining the observed behavior, it still does not fully explain the fact that almost no one buys any individual life annuities. Nothing forces people to choose 
between buying either the amount of annuities that would be optimal at actuarially fair prices or buying none at all. Hence showing under what conditions people would prefer no annuities at all to the amount they would purchase at actuarially fair prices still does not establish the conditions under which they would not buy some amount that is significant albeit less than the actuarially fair optimum. For the assumed values of $\alpha, R, \beta$ and $S$ underlying the simulations reported in Table 8, for example, and for an assumed annuity load factor of $I=1.40$ (the critical value for $\theta=24$ ), the strength of the bequest motive required to make the individual indifferent between purchasing private annuities equal to $1 \%$ of initial wealth (including Social security) and purchasing none at all is $\theta=343$ - far above $\theta=24$, yet still below the logical upper bound for $\theta$ given the assumed parameter values. Table 9 summarizes the results of analogous simulations based on various values of $S, R$ and $\beta$, reporting in each case the value of $\theta$ that renders the individual just indifferent between investing $1 \frac{8}{\circ}$ of initial wealth (including Social Security) in private annuities and purchasing none at all when the load factor is $\mathrm{L}=1.40 .^{24}$

Both because the quantitative importance of bequests in overall saving is a question with major implications for both positive and normative issues, $^{25}$ and also because there is little other way to evaluate the plausibility of values of $\theta$ within the logically admissible range, it is interesting to see just how large these results suggest that the typical bequest should be. Table 10 shows, for each of the combinations of parameter values considered in Table 9, and in each case for the value of the bequest motive parameter $\theta$ (as shown in Table 9) needed to render the individual indifferent between investing $1 \%$ of initial wealth in private 
BEQUEST MOTIVE STRENGTH NEEDED TO ELIMINATE ANNUITY PURCHASES

$\underline{S=.4} \quad \underline{S=.5} \quad \underline{S=.6}$

$\underline{R=1.01}$

$\begin{array}{lrrr}\beta=2 & 18 & 9 & 4 \\ \beta=3 & 169 & 58 & 18 \\ \beta=4 & 1488 & 343 & 74\end{array}$

$\mathrm{R}=1.04$

$\begin{array}{lrrr}\beta=2 & 10 & 5 & 3 \\ \beta=3 & 66 & 24 & 7 \\ \beta=4 & 419 & 105 & 22\end{array}$

Notes: Values shown are for $\theta$, just sufficient to eliminate initial annuity purchases equal to .01 of initial wealth.

Assumed values (other than $S, R$ and $\beta$ as shown) are $\alpha=.99$ and $L=I .40$. Calculations are for 65-year-old males. 
TABLE 10

RATIO OF EXPECTED BEQUEST TO FINAL PERIOD CONSUMPTION

$\underline{S=.4} \quad \underline{S=.5} \quad \underline{S=.6}$

$R=1.01$
$\beta=2$
3.40
2.40
1.60
$\beta=3$
4.77
3.34
2.25
$\beta=4$
5.56
3.85
2.63

$\underline{R=1.04}$
$\beta=2$
2.57
1.82
1.29
$\beta=3$
3.52
2.51
1.67
$\beta=4$
4.08
2.89
1.95

Notes: Values shown are ratios of expected bequest to final period consumption, given $\theta$ just large enough to eliminate initial annuity purchases equal to .01 of initial wealth.

Assumed values (other than $S, R$ and $\beta$ as shown are $\alpha=.99, I=1.40$ and as shown in Table 9.

Calculations are for 65-year-old males. 
annuities and purchasing none at all when the load factor is $\mathrm{L}=1.40$, the corresponding bequest/consumption ratio $\left(\mathrm{G}_{\mathrm{w}-\mathrm{x}} / \mathrm{C}_{\mathrm{w}-\mathrm{x}-1}\right)$. For the most part these estimates are closely bunched, despite the wide variation in the underlying parameter values, typically indicating a bequest equal to two to four times the final year's consumption. Especially for the lower end of the range, these estimates appear to be empirically plausible. ${ }^{26}$ Given the respective roles of $S, R$ and $\beta$ in affecting the demand for annuities in the model developed in section II, their corresponding roles here in determining the strength of bequest motive necessary to eliminate that demand (for a given load factor) is straightforward. The demand for individual life annuities is smaller as social security is more important, smaller as the rate of return is higher, and greater as people are more risk averse. Hence the bequest motive implied by the fact that few people buy individual life annuities is weaker as social Security is more important, weaker as the rate of return is higher, and stronger as people are more risk averse.

In sum, the results shown in Tables 9 and 10 indicate that for plausible sets of assumed parameter values the combination of an annuity load factor in the observed range (see again Table 3) and an empirically plausible positive bequest motive in the theoretically admissible range for altruistic bequests is sufficient to explain the absence of purchases of individual life annuities. This finding lends strength to the view that desired bequests are an important element in consumption-saving behavior. Moreover, when Social Security is less important and people are more risk averse, the bequest motive assumes an especially large role in explaining why so few people buy annuities. Under these circumstances the indicated bequest is at least four times final consumption. 
IV. Conclusion and Further Thoughts

The observed reluctance of most individuals in the United States to buy individual life annuities, and the concommitant approximately flat average age-wealth profile, stand in sharp contradiction to the standard life cycle model of consumption-saving behavior. The analysis in this paper lends support to an explanation for this phenomenon based on the interaction of an intentional bequest motive and annuity prices that are not actuarially fair.

Premiums charged for individual life annuities in the United States do include a load factor of 32-48 per dollar, or 18-33\% per dollar after allowing for adverse selection, in comparison to actuarially fair annuity values. Load factors of this size are not out of line with those on other familiar (and almost universally purchased) insurance products. Simulations of an extended model of life cycle saving and portfolio behavior, allowing explicitly for uncertain lifetimes and Social security, show that the load factor charged would have to be far larger than this to account for the observed behavior in the absence of a bequest motive. By contrast, the combination of a load factor in this range and a positive bequest motive can do so for some plausible values of the assumed underlying parameters. Moreover, if this combination of factors is leading elderly individuals to avoid purchasing life annuities, it implies a typical bequest that is fairly large in comparison to their consumption.

As the authors' earlier work has already emphasized, caution is appropriate in relying on these conclusions without further research. Although the model used here does generalize the standard life-cycle model in several potentially important ways, it still excludes a priori a variety of further possible explanations for the observed behavior: ${ }^{27}$ First, many 
people at least say that they choose stable age-wealth profiles, rather than either buying annuities or simply consuming out of wealth, not because of mortality considerations but from fear of the consequences of catastrophic illness. Second, while the analysis here follows the recent literature by implicity working in real terms, the individual life annuities available in U.S. markets quarantee specified nominal payments. Third, the analysis here does not allow for several more complex kinds of possible interactions within families, including, for example, either non-altruistic ("manipulative") bequests or intra-family risk sharing. 28 Finally, in contrast to the reliance here (and in just about all of the available literature on the subject) on the standard theory of expected utility maximization, there is evidence that, especially when the prospect of rare events is involved, individuals systematically overweight the probability of rare events. 29

These further possible explanations for the fact that few people purchase individual life annuities remain as objects for future research. 
MEAN LOAD FACTOR FOR LIFE ANNUITY PREMIUMS

Mortality Probabilities:

Interest Rate:
General Population

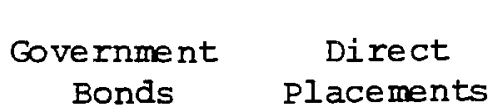

Annuity Purchasers

Direct Placements

Premium and Load Factors for 65-Year-old Females:

$\begin{array}{lllll}\text { Ten-Largest Mean } & 1.26 & 1.42 & 1.18 & 1.35 \\ \text { Ten-Largest High } & 1.34 & 1.52 & 1.26 & 1.44 \\ \text { Ten-Largest Low } & 1.18 & 1.33 & 1.11 & 1.26 \\ \text { Complete-Sample Low } & 1.15 & 1.30 & 1.08 & 1.23\end{array}$

Premium and Load Factors for 70-Year-old Males:

$\begin{array}{lcccc}\text { Ten-Largest Mean } & 1.30 & 1.43 & 1.16 & 1.29 \\ \text { Ten-Largest High } & 1.37 & 1.51 & 1.22 & 1.36 \\ \text { Ten-Largest Low } & 1.24 & 1.36 & 1.11 & 1.23 \\ \text { Complete-Sample Low } & 1.18 & 1.30 & 1.06 & 1.17\end{array}$

Premium and Load Factors for 75-Year-Old Males:

$\begin{array}{lcccc}\text { Ten-Largest Mean } & 1.29 & 1.40 & 1.15 & 1.26 \\ \text { Ten-Iargest High } & 1.35 & 1.47 & 1.21 & 1.33 \\ \text { Ten-Largest Iow } & 1.23 & 1.34 & 1.10 & 1.21 \\ \text { Complete-Sample Low } & 1.15 & 1.25 & 1.03 & 1.13\end{array}$




\section{Footnotes}

*Harvard University and Board of Governors of the Federal Reserve System, respectively. We are grateful to Andrew Abel, Glenn Hubbard, Laurence Kotlikoff and Lawrence Summers for helpful comments on an earlier paper; to Amy Bassan, Robert Rubinstein, Francis Schott, Mark Slutzky, Michael Winterfield, as well as the Equitable Life Assurance Society, A.M. Best Publishers and the American Council of Life Insurance, for help in gathering data; and to the National Bureau of Economic Research and the Alfred P. Sloan Foundation for research support.

1. See, for example, Mirer (1979) and Hubbard (1983).

2. The Retirement History Survey indicates that only $2 \%$ of the elderly population own individual annuities of any sort; see, for example, Friedman and Sjogren (1980).

3. See Friedman and Warshawsky. (1985).

4. This dispersion probably reflects search costs; see, for example, Pratt et al. (1979). Alternatively, it could reflect different marketing choices by different insurers.

5. The exact expression used is $\sum_{t=1}^{w-x-1}(1+r)^{-t} p_{x t}$ where $w$ is the assumed maximum length of life (here taken to be 110 years), $x$ is the age at the date of issue (here 65 years), $r$ is the relevant interest rate, and $P_{x t}$ is the probability that an individual of age $x$ at time $t=1$ will survive to any year $t>1$. These annual calculations are then converted to a monthly basis.

6. The calculations rely on the 1970 tables for years 1968-70, on the 1980 tables for years 1980-83, and on both tables (weighted) for years 1971-79. See Faber (1982) for a complete description of the U.S. Iife Tables, and Wetterstrand (1983) for a discussion of improvements in mortality probabilities. In the calculations for females summarized in Appendix Table 1 below, the corresponding adjustment factors are .98 and .99 .

7. See Rothschild and Stiglitz (1976) for an analysis of the principles underlying this kind of adverse selection.

8. See Society of Actuaries (1983) for the actual company experience tables.

9. This latter comparison is the relevent one from the perspective of the insurer. Informal discussions with insurers suggested that, of this 33 \% per dollar, roughly lle reflected transactions costs (narrowly defined), $8 \xi$ taxes, and $14 \xi$ return to capital at risk. This break-down is at best only suggestive, however.

10. The small probability that a 65 -year-old male will survive past age 100 is simply ignored for purposes of this comparison. 
11. This section draws heavily on Friedman and Warshawsky (1985); see that paper for additional details and references to relevant literature.

12. In fact, Fischer's model is really an annuity model, despite his application of it to the demand for life insurance.

13. Probabilities $p_{t}$ and $q_{t+1}$ are, of course, conditional on initial age $x$. Writing them as $p(x)_{t}$ and $q(x)_{t+1}$ would be appropriate but would clutter an already cumbersome notation. Conditionality on $x$ is to be understood, here and below.

14. In a more general context it would also be necessary to take account of labor income. The focus of this paper, however, is on the elderly retired population.

15. As in Fischer (1973), the assumption of one-period annuities makes the analysis tractable. The annuities actually available for purchase in the United States are instead life annuities.

16. The model as written here imposes no nonnegativity constraint on choice parameter A - that is, it does not explicitly preclude short sales of annuities. For most reasonable values of the given parameters, however, large short sales are not optimal anyway. If they were, imposing a nonnegativity constraint in solving the model would be straightforward.

17. The time profile in (17) is from Fischer's Appendix Table A2, extended to age 110. Reasoning analogous to that underlying Abel's (1984) model of life insurance markets suggests that the results could be very sensitive to whether the value of bequests is rising or falling with $t$. In particular, a sufficiently negatively sloped bequest motive can, under some circumstances, give rise to a negative demand for annuities. The after-age -65 portion of Fischer's time profile, used here, makes $b_{t}$ decline approximately in step with $\alpha^{t}$ for $\alpha=.99$ as assumed below.

18. Friedman and Warshawsky (1985) indicate other circumstances under which $\theta$ would not be bounded.

19. Grossman and Shiller (1981) found evidence consistent with a relative risk aversion coefficient roughly equal to 4 . Bodie et al. (1985) also used this value.

20. Wealth held in annuity form is valued at the presented expected value.

21. In other words, any approximately flat consumption stream exceeding $3.38 \%$ of initial wealth each year $(7.20 \%$ as in the third column of Table 5, divided by 2.13) would be preferable to the declining stream shown in the first column. 
22. Friend and Blume (1975) found evidence indicating a relative risk aversion coefficient roughly equal to 2 .

23. One-half is about the fraction of total wealth constituted by Social security and private pensions for the average retired elderly individual in the United States; see the evidence provided by Kotlikoff and Smith (1983), Table 3.7.19 (p. 127).

24. The results shown in Table 9 follow from searching over $\theta$, given the assumed values of the other parameters. For purposes of comparison to the analysis by Kotlikoff and Spivak (1981), the $\theta$ values corresponding to $\beta=1.25$ are (in order, from top to bottom in the table) $3,2,1,2,1.5$ and 1 .

25. See, for example, Kotlikoff and Summers (1981).

26. For males Menchik and David (1982 p. 193, Table 1), reported a median bequest equal to 2.1 times annual median labor income (defined as one-fortieth of average annual labor earnings), and a mean bequest equal to 4.2 times mean annual labor income.

27. See Friedman and Warshawsky (1985) for a brief discussion of several of these other possible explanations.

28. See, for example, Bernheim et al. (1984) on non-altruistic bequests and Kotlikoff and Spivak (1981) on intra-family risk sharing.

29. See, for example, Kahneman and Tversky (1979). 


\section{References}

Abel, Andrew B. "The Effects of Social Security in the Presence of Perfect Annuity Markets." Mimeo: Harvard University, 1984.

Bernheim, B. Douglas, Shleifer, Andrei, and Summers, Lawrence H. "Bequests as a Means of Payment." Mimeo: National Bureau of Economic Research, 1984 .

Bodie, Zvi, Kane, Alex, and McDonald, Robert. "Inflation and the Role of Bonds in Investors' Portfolios." Friedman (ed.), Corporate Capital structures in the United states. Chicago: University of Chicago Press, 1985 .

Davies, James B. "Uncertain Lifetime, Consumption, and Dissaving in Retirement." Journal of Political Economy, 89 (June, 1981), 561-577.

Faber, J. Iife Tables for the United States: 1900-2050. Actuarial Study No. 87. Washington: Social Security Administration (Office of the Actuary)', 1982 .

Fischer, Stanley. "A Iife Cycle Model of Life Insurance Purchases." International Economic Review, 14 (February, 1973), 132-152.

Friedman, Benjamin M., and Warshawsky, Mark. "The Cost of Annuities: Implications for Saving Behavior and Bequests." Mimeo: National Bureau of Economic Research, 1985.

Friedman, Joseph, and Sjogren, Jane. "Assets of the Elderly as They Retire." Mimeo: Social Security Administration, 1980.

Friend, Irwin, and Blume, Marshall E. "The Demand for Risky Assets." American Economic Review, 65 (December, 1975), 900-922.

Grossman, Sanford J., and Shiller, Robert J. "The Determinants of the Variability of Stock Prices." American Economic Review, 71 (May, 1981), 222-227.

Hubbard, R. Glenn. "Uncertain Iifetimes and the Impact of Social Security on Individual Wealth Holding." Mimeo: Harvard University, 1983.

Kahneman, Daniel, and Tversky, Amos. "Prospect Theory: An Analysis of Decision Under Risk." Econometrica, 47 (March, 1979), 263-292.

Kotlikoff, Laurence J., and Smith, Daniel E. Pensions in the American Economy. Chicago: University of Chicago Press, 1983.

Kotlikoff, Iraurence J., and Spivak, Avia. "The Family as an Incomplete Annuity Market." Journal of Political Economy, 89 (April 1981), 372-391.

Kotlikoff, Laurence J., and Summers, Lawrence H. "The Role of Intergenerational Transfers in Aggregate Capital Accumulation." Journal of Political Economy, 89 (August, 1981), 706-732. 
Menchik, Paul L., and David, Martin. "The Incidence of a Lifetime Consumption Tax." National Tax Journal, 35 (June, 1982), 189-203.

Mirer, Thad W. "The Wealth-Age Relation Among the Aged." American Economic Review, 69 (June, 1979), 435-443.

Pratt, John W., Wise, David A., and Zeckhauser, Richard. "Price Differences in Almost Competitive Markets." Quarterly Journal of Economics, 93 (May, 1979), 189-212.

Rothschild, Michael, and Stiglitz, Joseph. "Equilibrium in Competitive Insurance Markets: An Essay on the Economics of Imperfect Information." Quarterly Journal of Economics, 90 (November, 1976), 629-649.

Society of Actuaries. "Report to the Committee to Recommend a New Mortality Basis for Individual Annuity Valuation (Derivation of the 1983 Table a)." Transactions of the Society of Actuaries, $33(1983), 675-750$.

Wetterstrand, W.H. "Parametric Models for Iife Insurance Mortality Data: Gompertz's Law Over Time." Transactions of the Society of Actuaries, 33 (1983), 159-179. 